\title{
Perawatan Diri Selama Menstruasi pada Remaja Putri di SMA Negeri 10 Palangka Raya
}

\author{
Self-Care During Menstruation in Adolescent Girls at $10^{\text {th }}$ Public High Schools Palangka Raya
}

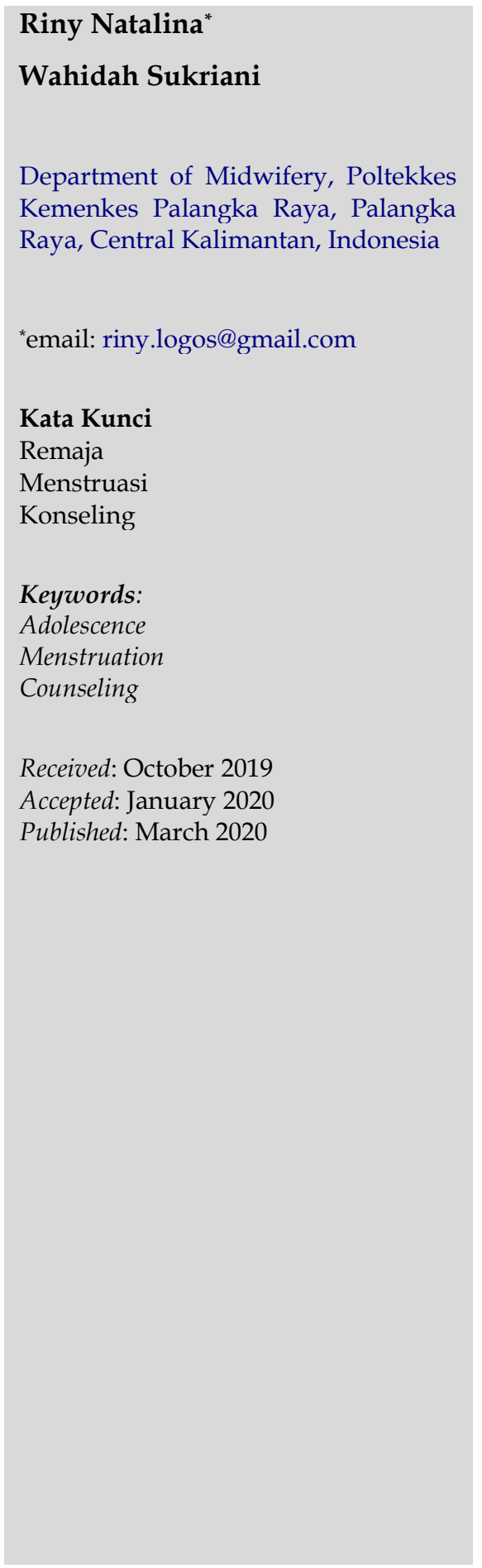

\begin{abstract}
Abstrak
Remaja merupakan masa dimana seseorang bertransisi dari masa kanakkanak menuju kedewasaan yang ditandai dengan berbagai perubahan baik secara fisik, kognitif, sosial maupun emosi. Diantaranya adalah Pubertas, pubertas menyebabkan remaja memiliki kebutuhan khusus terhadap kebersihan. Salah satu hal yang penting diperhatikan secara lebih adalah perawatan diri terutama pada saat menstruasi. Pada remaja perempuan, pubertas ditandai salah satunya dengan adanya menstruasi pertama atau yang disebut juga dengan menarche. Personal Hygiene menstruasi merupakan isu kritis sebagai determinan status kesehatan remaja yang akan berpengaruh dalam kehidupan masa tua. Buruknya personal hygiene berpengaruh besar terhadap morbiditas dan komplikasi. Membiasakan diri dengan perilaku hygienis. Perilaku hygienis pada saat menstruasi tidak akan terjadi begitu saja, namun merupakan proses yang dipelajari karena individu mengerti dampak positif atau negatif suatu perilaku yang terkait dengan keadaan menstruasi Pendidikan kesehatan reproduksi pada dasarnya merupakan upaya untuk memberikan pengetahuan tentang fungsi, sistem dan proses reproduksi sebagai akibat pertumbuhan dan perkembangan manusia. Sekaligus memantapkan moral, etika serta membangun komitmen agar tidak terjadi penyalah gunaan organ reproduksi tersebut. Pusat Informasi dan Konseling Remaja (PIK-R) merupakan sebuah program yang mana dikembangkan dari, oleh dan untuk remaja yang mana salah satu kegiatan di dalamnya adalah pemberian informasi tentang kesehatan reproduksi remaja.
\end{abstract}

\begin{abstract}
Teenage is a time when someone transitioned from childhood to adulthood characterized by various changes both physically, cognitively, socially and emotionally. Among them is Puberty, puberty causes adolescents to have special needs for hygiene. One of the important things to pay more attention to is self-care, especially during menstruation. In adolescent girls, puberty is characterized by one of the first menstrual periods or also called menarche. Personal Hygiene menstruation is a critical issue as a determinant of the health status of adolescents who will influence the life of old age. Poor personal hygiene has a major effect on morbidity and complications. Familiarize yourself with hygienic behavior. Hygienic behavior during menstruation will not happen as well, but it is a learned process because individuals understand the positive or negative effects of behavior related to menstruation. Reproductive health education is basically an effort to provide knowledge about the functions, systems, and processes of reproduction as a result of human growth and development. At the same time establishing morals, ethics and building a commitment to avoid misuse of the reproductive organs. The Youth Information and Counseling Center (PIK-R) is a program which is developed from, by and for adolescents where one of the activities in it is providing information about adolescent reproductive health.
\end{abstract}




\section{PENDAHULUAN}

Menstruasi pertama pada remaja perempuan biasanya terjadi antara umur 10,5 sampai 15 tahun, dengan ratarata terjadi pada usia 12 tahun. Pada awal terjadi menstruasi, beberapa remaja menganggap menstruasi sebagai pengalaman yang menakutkan dan menimbulkan distres (Hockenberry \& Wilson, 2009). Hal ini dapat disebabkan karena kurangnya pemahaman remaja tentang perubahan yang akan terjadi saat pubertas. Beberapa di antaranya juga menganggap menstruasi sebagai hal yang sensitif dan tabu untuk diceritakan sehingga mereka lebih tertutup dan malu untuk bercerita pada orang lain, bahkan orang tua (Dasgupta \& Sankar, 2008). Pada akhirnya seorang remaja akan kekurangan informasi karena tidak mendapatkan pengetahuan yang memadai mengenai perawatan diri saat menstruasi terutama dari orang tua.

Salah satu yang sangat ditekankan bagi perempuan yang tengah mengalami menstruasi adalah pemeliharaan kebersihan diri (Phytagoras, 2017). Untuk menjaga kebersihan dan kesehatan, idealnya penggunaan pembalut selama menstruasi harus diganti secara teratur 4 sampai 5kali sehari atau setiap 4 jam sekali, apalagi jika sedang banyak-banyaknya. Setelah mandi atau buang air, vagina harus dikeringkan dengan tisu atau handuk agar tidak lembab. Selain itu pemakaian celana dalam hendaknya bahan yang terbuat dari yang mudah menyerap keringat (Phonna et al., 2017).

Kebiasaan menjaga kebersihan, termasuk kebersihan organ-organ seksual atau reproduksi merupakan awal dari usaha menjaga kesehatan. Pada saat menstruasi, pembuluh darah dalam rahim terbuka sehingga sangat mudah terkena infeksi (Yanti et al., 2014). Perawatan kesehatan dan kebersihan adalah hal yang banyak dibicarakan dalam masyarakat. Biasanya hal ini diajarkan oleh orang tua kita sejak kita masih kecil. Tetapi, karena orang tua seringkali tidak merasa nyaman membicarakan masalah seksual, biasanya masalah kesehatan dan kebersihan yang dibicarakan hanya menyangkut hal yang umum saja sedangkan urusan kesehatan organ seksual jarang kita dapatkan dari mereka (Sarwono, 2011; Liza, 2019).

Menurut penelitian yang dilakukan oleh Suryati (2012) mengenai perilaku kebersihan remaja saat menstruasi menunjukkan bahwa ada pengaruh atau hubungan terhadap perilaku kebersihan pada saat menstruasi pada remaja putri. Variabel yang terbukti berhubungan secara statistik bermakna $(a=0,05)$ terhadap perilaku kebersihan pada saat menstruasi adalah pendidikan orang tua, pengetahuan, sikap, ketersediaan fasilitas alat pembersih dan dukungan teman sebaya. Dengan demikian perlu upaya mempertahankan dan meningkatkan perilaku kebersihan saat menstruasi melalui peningkatan pengetahuan tentang kesehatan reproduksi yang tepat agar saling memberi informasi antara teman, serta komunikasi antara guru, petugas kesehatan dan orangtua siswi, dan siswi lebih ditingkatkan (Bujawati et al., 2017).

\section{METODOLOGI}

Kegiatan pengabdian masyarakat ini dilakukan pada bulan September - Oktober 2018 di SMAN 10 Palangka Raya dengan sasaran remaja putri usia 15 sampai dengan 18 tahun yang berjumlah 6 orang. Kegiatan ini terbagi dalam 3 tahap yaitu:

\section{Tahap Perencanaan}

Koordinasi dengan sekolah terkait siswa yang akan diikutkan dalam kegiatan dan pembuatan alat bantu yaitu leaflet dan booklet

2. Tahap Pelaksanaan

Pada tahap pelaksanaan dilakukan penyampaian materi tentang perawatan diri selama menstruasi terhadap 6 siswi yang di tunjuk oleh sekolah dan 
dilakukan pelatihan konseling tentang perawatan diri selama menstruasi.

3. Tahap Evaluasi

Evaluasi dilakukan dua kali. Evaluasi dilakukan dengan cara siswi yang telah disampaikan materi tentang perawatan diri selama mentruasi dan dilakukan pelatihan konseling melakukan pemberian informasi dan konseling tentang perawatan diri selama menstruasi kepada teman sebaya putri sebanyak 18 orang di SMAN 10 Palangka Raya dengan di damping oleh tim pengabdian.

\section{HASIL DAN PEMBAHASAN}

Berdasarkan evaluasi menggunakan instrument penilaian proses layanan konseling bagi siswa oleh konselor sebaya maka didapatkan hasil sebagamana ditunjukkan pada Tabel I. Pada Tabel I menunjukkan terdapat peningkatan kemampuan konselor dalam memberikan konseling terhadap teman sebaya dalam perawatan diri selama menstruasi. Sementara pada Tabel II menunjukkan bahwa layanan konseling oleh konselor sebaya dinilai baik oleh teman sebaya siswi SMAN 10 Palangka Raya.

Tabel I. Penilaian Proses Layanan Konseling

\begin{tabular}{ccc}
\hline Pertemuan Ke & Kriteria hasil & Keterangan \\
\hline 1 & Baik & 6 orang konselor \\
2 & Baik & 3 orang konselor \\
3 & Sangat Baik & 3 orang konselor \\
& Baik & 2 orang konselor \\
& Sangat Baik & 4 orang konselor \\
\hline
\end{tabular}

Tabel II. Penilaian Proses Layanan Konseling

\begin{tabular}{ccc}
\hline Pertemuan Ke & Kriteria hasil & Keterangan \\
\hline 1 & Baik & 4 orang \\
& Sangat Baik & 2 orang \\
2 & Baik & 2 orang \\
& Sangat Baik & 4 orang \\
3 & Sangat Baik & 6 orang \\
\hline
\end{tabular}

Kegiatan Pengabdian masyarakat tentang peningkatan kapasitas PIK-R melalui konselor sebaya dengan topik perawatan diri selama menstruasi menunjukkan perubahan yang baik. Dalam upaya peningkatan kapasitas PIK-R, konselor sebaya terlebih dahulu dibekali dengan pengetahuan mengenai perawatan diri selama menstruasi. Pada pembekalan konselor sebaya ini terjadi peningkatan pengetahuan para konselor sebaya mengenai reproduksi perempuan.

Personal Hygiene menstruasi merupakan isu kritis sebagai determinan status kesehatan remaja yang akan berpengaruh dalam kehidupan masa tua. Buruknya personal hygiene berpengaruh besar terhadap morbiditas dan komplikasi (Aniebue et al, 2009). Membiasakan diri dengan perilaku hygienis. Perilaku hygienis pada saat menstruasi tidak akan terjadi begitu saj, namun merupakan proses yang dipelajari karena individu mengerti dampak positif atau negatif suatu perilaku yang terkait dengan keadaan menstruasi (Bujawati et al., 2017). Kurangnya kesadaran kebersihan menstruasi dan perawatan selama menstruasi yang disebabkan oleh kurangnya pendidikan yang berhubungan dengan menstruasi dan kebersihan menstruasi.

Pendidikan kesehatan reproduksi pada dasarnya merupakan upaya untuk memberikan pengetahuan tentang fungsi, sistem dan proses reproduksi sebagai akibat pertumbuhan dan perkembangan manusia. Sekaligus memantapkan moral, etika serta membangun komitmen agar tidak terjadi penyalah gunaan organ reproduksi tersebut (Kementerian Kesehatan Republik Indonesia, 2011). Pusat Informasi dan Konseling Remaja (PIK-R) merupakan sebuah program yang mana dikembangkan dari, oleh dan untuk remaja yang mana salah satu kegiatan di dalamnya adalah pemberian informasi tentang kesehatan reproduksi remaja (Badan Kependudukan dan Keluarga Berencana Nasional, 2011).

Pada usia remaja hubungan pertemanan merupakan hubungan akrab yang diikat oleh miant yang sama 
kepentingan yang sama dan saling membagi perasaan, saling tolong menolong untuk memecahkan masalah bersama. Teman merupaka ntahap awal dalam pergaulan remaja. Pada usia ini mereka bisa juga mendengar pendapat pihak ketiga. Pada usia dua belas tahun ke atas, ikatan emosi bertambah kuat dan mereka makin saling membutuhkan, namun mereka saling memberi kesempatan mengembangkan kerpibadian masing-masing (Sarwono, 2011).

Bagi remaja, teman sebaya mendapatkan perhatian prioritas utama daripada keluarga. Hal tersebut mengganggap teman sebaya lebih memberikan pengertian, dukungan dan penampungan. Adanya teman sebaya, remaja dapat dengan mudah untuk membagi perasaan atau kesulitan-kesulitannya. Teman selalu siap menampung masalah karena merasa senasib. Dalam hal ini sering mendapat persetujuan dan penerimaan dari teman sebayanya. Itulah sebabnya banyak remaja lebih terbuka pada teman sebaya. Salah satu program dari PIK-R adalah mengoptimalkan peran teman sebaya untuk dapat memberikan konseling bagi sesama remaja terkait dengan kesehatan reproduksi remaja. Konseling yang diberikan oleh teman sebaya diharapkan dapat lebih dipercaya, sehingga remaja lebih terbuka untuk menyampaikan setiap masalah yang dihadapi (Kementerian Kesehatan Republik Indonesia, 2011).

\section{KESIMPULAN}

Kegiatan pembinaan dan peningkatan kapasitas PIKdengan topik perawatan diri selama menstruasi pada remaja perempuan di SMAN 10 Kota Palangka Raya menunjukkan adanya perbaikan pengetahuan mengenai perawatan diri selama menstruasi, adanya peningkatan keterampilan konselor sebaya dalam PIK-R dalam melakukan konseling sebaya mengenai perawatan diri selama menstruasi, serta terbentuknya sikap para siswi melakukan perawatan diri selama menstruasi. Agar pembinaan dan peningkatan kapasitas PIK-R ini dapat dilakukan secara terus-menerus dengan materi-materi lainnya, agar dapat meningkatkan pengetahuan remaja tentang kesehatan reproduksi remaja.

\section{UCAPAN TERIMA KASIH}

Ucapan terimakasih ditujukan kepada Poltekkes Kemenkes Palangka Raya yang telah memberikan kesempatan bagi kami untuk melakukan pengabdian pada masyarakat, serta sivitas akademika yang telah membantu pelaksanaan kegiatan Pengabdian.

\section{REFERENSI}

Aniebue, U.U., Aniebue, P.N., Nwankwo, T.O. 2009. The impact of pre-menarcheal training on menstrual practices and hygiene of Nigerian school girls. The Pan African Medical Journal. 2:9.

Badan Kependudukan dan Keluarga Berencana Nasional. 2011. Panduan pengelolaan Pusat informasi dan konseling kesehatan reproduksi remaja. Jakarta: Badan Kependudukan dan Keluarga Berencana Nasional.

Bujawati, E., Raodhah, S., Indriyanti, I. 2017. Higiene: Jurnal Kesehatan Lingkungan. 3(1):1-9.

Dasgupta, A., Sankar, M. 2008. Menstrual Hygiene: How Hygienic is the Adolescent Girl?. Indian Journal of Community Medicine. 33(2):77-80. https://dx.doi.org/10.4103/0970-0218.40872

Hockenberry, M.J., Wilson, D. 2009. Wong's essentials of pediatric nursing. $8^{\text {th }}$ ed. Canada: Mosby.

Kementerian Kesehatan Republik Indonesia. 2011. Modul Pelatihan Pelayanan Kesehatan Peduli Remaja. Bagi Tenaga Kesehatan. Jakarta: Kementerian Kesehatan Republik Indonesia.

Liza, L. 2019. Gambaran Pengetahuan dan Sikap Remaja Putri terhadap Personal Higiene saat Menstruasi di SMP N 19 Kota Jambi Tahun 2018. Jurnal Akademika Baiturrahim Jambi. 
8(2):267-275.

http://dx.doi.org/10.36565/jab.v8i2.168

Phonna, R., Diba, F., Yuswardi, Maulina. 2017. Upaya Menjaga Kebersihan Saat Menstruasi Pada Remaja Putri. Idea Nursing Journal. 9(2):14-20.

Phytagoras, K.C. 2017. Personal Hygiene Remaja Putri Ketika Menstruasi. Jurnal Promkes: The Indonesian Journal of Health Promotion and Health Education. 5(1):13-26. http://dx.doi.org/10.20473/jpk.V5.11.2017.13 $-26$

Sarwono, S.W. 2011. Psikologi Remaja Edisi Revisi. Jakarta: Rajawali Pers.

Suryati, B. 2012. Perilaku Kebersihan Remaja Saat Menstruasi. Jurnal Health Quality. 3(1):54-65.

Yanti, D.S., Agrina, Elita, V. 2014. Hubungan Pengetahuan Remaja Putri Tentang Menstruasi Terhadap Perilaku Higienis Pada Saat Menstruasi. Jurnal Online Mahasiswa Program Studi Ilmu Keperawatan Universitas Riau. 1(2):1-8. 